\title{
Screening of bottle gourd cultivars against alternaria leaf spot disease caused by Alternaria alternata under natural epiphytic conditions at Tarnab, Peshawar, Pakistan
}

Mehran Gul ${ }^{1}$, Irshad Ali Khan ${ }^{1 *}$, Muhammad Ibrahim ${ }^{1}$, Abdur Rehman $^{2}$, Imran Shinwari ${ }^{2}$, Saqib Mumtaz ${ }^{3}$, Muhammad Adil ${ }^{1}$ and Sohail Ahmad ${ }^{1}$

1. Department of Agriculture, The University of Swabi, Khyber Pakhtunkhwa, Pakistan

2. Agriculture Research Institute, Tarnab, Peshawar, Khyber Pakhtunkhwa, Pakistan

3. Department of Biosciences, COMSATS University, Islamabad, Pakistan

*Corresponding author's email: irshad_1242000@yahoo.com

Citation

Mehran Gul, Irshad Ali Khan, Muhammad Ibrahim, Abdur Rehman, Imran Shinwari, Saqib Mumtaz, Muhammad Adil and Sohail Ahmad. Screening of bottle gourd cultivars against alternaria leaf spot disease caused by Alternaria alternata under natural epiphytic conditions at Tarnab, Peshawar, Pakistan. Pure and Applied Biology. Vol. 11, Issue 1, pp254-258. http://dx.doi.org/10.19045/bspab.2022.110027

\begin{tabular}{llll}
\hline \hline Received: 17/03/2021 & Revised: 18/05/2021 & Accepted: 28/05/2021 & Online First: 15/06/2021 \\
\hline \hline
\end{tabular}

\section{Abstract}

This research was conducted with the objective to find out the response of four different Bottle gourd (lagenaria siceraria) cultivars against the fungal disease Alternaria leaf spot caused by Alternaria alternata under natural conditions at the Agricultural Research Institute (ARI), Tarnab, Peshawar during the year 2019. The cultivars (Anokhi, Super B2, C-01 and ISC 441) were grown at the site based on the previous crop history. All the cultivars were provided equal agronomic practices and conditions. Results indicate that cultivar (C-01) showed reduced disease symptoms and was highly resistant (11.667) while ISC 441 (45.00) was the most susceptible cultivar. Based on the results obtained, we conclude that cultivar (C-01) is the most resistant cultivar against Alternaria leaf spot and should be recommended for growing in the field. Furthermore, the research will help scientific community in specific and farmers in general to boost higher yield and reduce economic losses by cultivating the more resistant variety against the said fungal disease. Further research is needed to be conducted on the screening of Bottle gourd cultivars against Alternaria alternata in other parts of the country.

Keywords: Alternaria Leaf Spot; Bottle guard; C-01; ISC 441; Varieties

\section{Introduction}

Bottle-gourd (Lagenaria siceraria (Mol.) Standl.), is a summer vegetable crop in Pakistan and belongs to Cucurbitaceous family [1]. In Pakistan it is grown on (5492) hectare area with production of (55640) tons, while in Khyber Pakhtunkhwa it occupies (530) hectare with production of (4600) thousand tons [2].

Bottle gourd is a cross pollinated crop and well-drained sandy loam soil is recommended for its growing. It requires pH 6.0-6.7, but can also tolerate alkaline soils with $\mathrm{pH}$ 8.0. Approximately $3-4 \mathrm{~kg}$ of seeds are required for cultivating one 
hectare of land. Row to row and plant to plant distance $2.0-2.5 \mathrm{~m}$ and $45-60 \mathrm{~cm}$ respectively is highly recommended. Best sowing time is February-March, June-July and November-December. In summer season it needs 6-7 irrigations and in total, 9 irrigations are required.

This vegetable is a rich source of vitamins, iron and minerals and an excellent diet for people having digestive problems. The pulp has cooling and antibilious effect. The seed oil is applied externally in headache [3]. The fruits contain $0.2 \%$ protein, $2.9 \%$ carbohydrates, $0.5 \%$ fat and $11 \mathrm{mg}$ of vitamin $\mathrm{C}$ per $100 \mathrm{~g}$ fresh weight [4]. The fruit possess moisture $96.3 \%$, mineral matter $0.5 \%$, calcium $0.002 \%$ and phosphorus $2<0.01 \%$. Other mineral elements reported to be present are viz. iron $(0.7 \mathrm{mg} / 100 \mathrm{~g})$, sodium (11.0mg/100g), potassium $(86.0 \mathrm{mg} / 100 \mathrm{~g})$ and iodine $(4.5 \mathrm{mg} / \mathrm{kg})$. The leaves of the bottle gourd contain cucurbiticin, vitamin B. Vitamin D and traces of vitamin E. Vegetables are highly beneficial for maintenance of human health, maintaining alkaline reserve of body and prevention of diseases owing to presence of sufficient quantities of carbohydrates, minerals and vitamins in them [5].

This vegetable is attacked by many fungal diseases including Alternaria leaf blight and Cercospora leaf spot [6]. The bottle gourd is a natural host of viruses, fungi (powdery mildew, downy mildew, Alternaria leaf spot, anthracnose, fusarium wilt) and nematodes that cause serious losses in the quantity and quality of the fruits. Among them Alternaira leaf spot is one of the important diseases of the bottle gourd in Pakistan. The disease is favored by warm humid conditions with increase in disease from $15-25^{\circ} \mathrm{C}$ and declines between 30 and $37^{\circ} \mathrm{C}$. Relative humidity (RH) also influenced infection with limited lesion development observed at $\leq 92 \% \quad \mathrm{RH}$ whereas incubation at 98 and $100 \% \mathrm{RH}$ resulted in large lesions. The optimum conditions determined for lesion development were incubation at $25-30^{\circ} \mathrm{C}$ with $98-100 \%$ RH. Wounded leaf tissue was significantly more susceptible to infection than non-wounded leaf tissue and senescent leaves were more susceptible than newly emerged leaves. Variation in pathogenicity was also observed on senescent leaves infected with different pathotypes of Alternaria alternata. [7].

The symptoms appear as small, yellowbrown spots with a yellow or green halo which first appear on the oldest leaves; as the disease progresses, lesions expand and become large necrotic patches, often with concentric patternation; lesions coalesce, leaves begin to curl and eventually die (Fig. $1)$.

\section{Materials and Methods}

To find out the response of 4 different Bottle gourd cultivars against the Alternaria leaf spot under natural field conditions, the experiment was conducted at Agricultural Research Institute (ARI), Tarnab, Peshawar, Pakistan using RCBD design during summer season of 2019 based on previous crop history (Fig. 2). The experiment consists of 4 bottle gourd cultivars viz ; ( C-01, Super B2, Anokhi and ISC 441). The plant size was maintained as Width (4.5ft) Repetition (3) and the length of field is (36 ft.) $=486 \mathrm{ft} 2$. Agronomic practices were applied for all treatments equally with 1.5 and 1.0 feet as row to row and plant to plant distance.

\section{Identification of the pathogen}

Freshly leaf samples were collected and mounted on temporary slides for fungal conidial observation and identification under a microscope $[8,9]$.

\section{Disease severity}

Data on disease severity were recorded following the onset of Altarnaria leaf spot symptoms, using the disease rating scale (Table 1) given by [10]. 


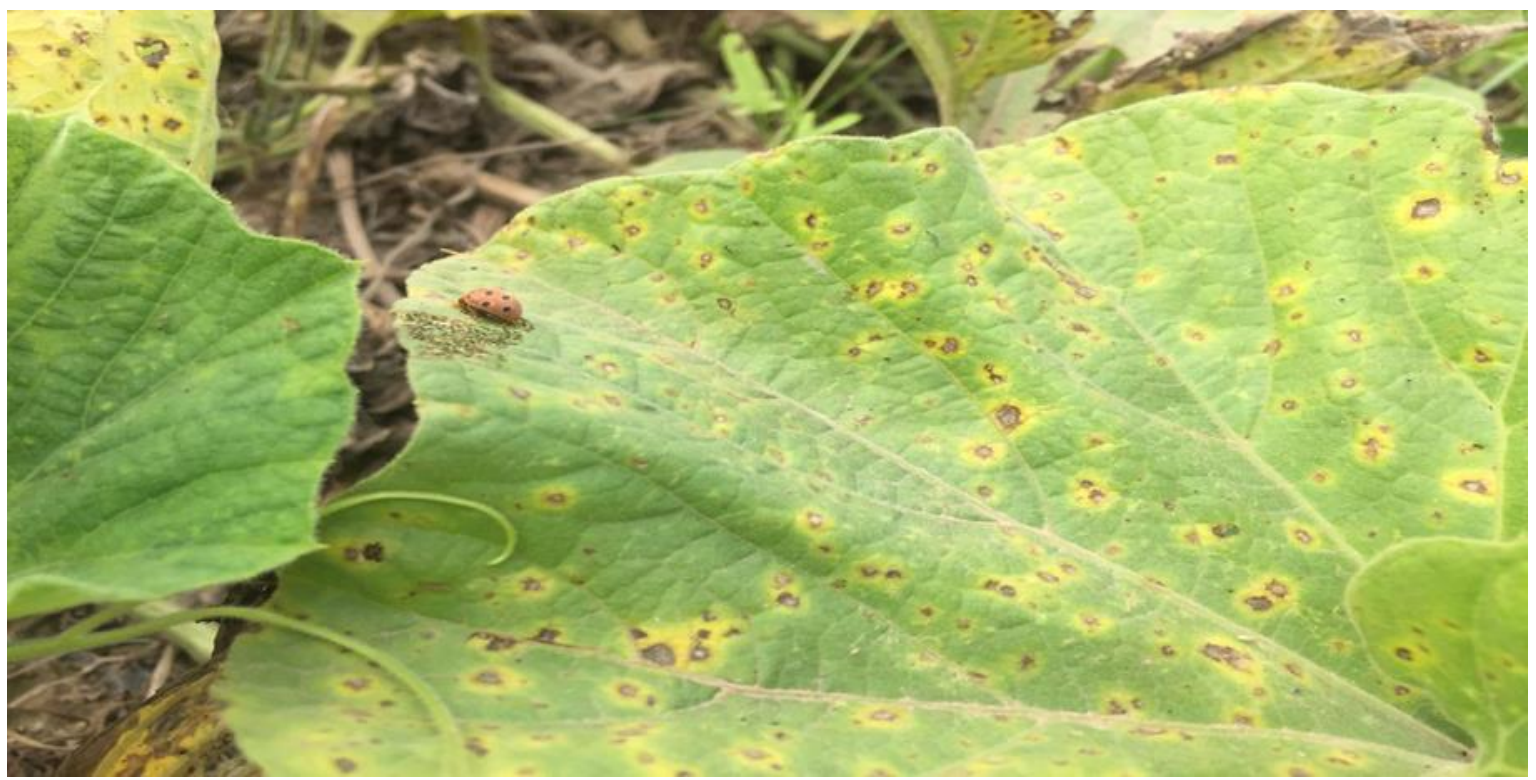

Figure 1. Symptoms on Bottle gourd leaf caused by Alternaria alternate

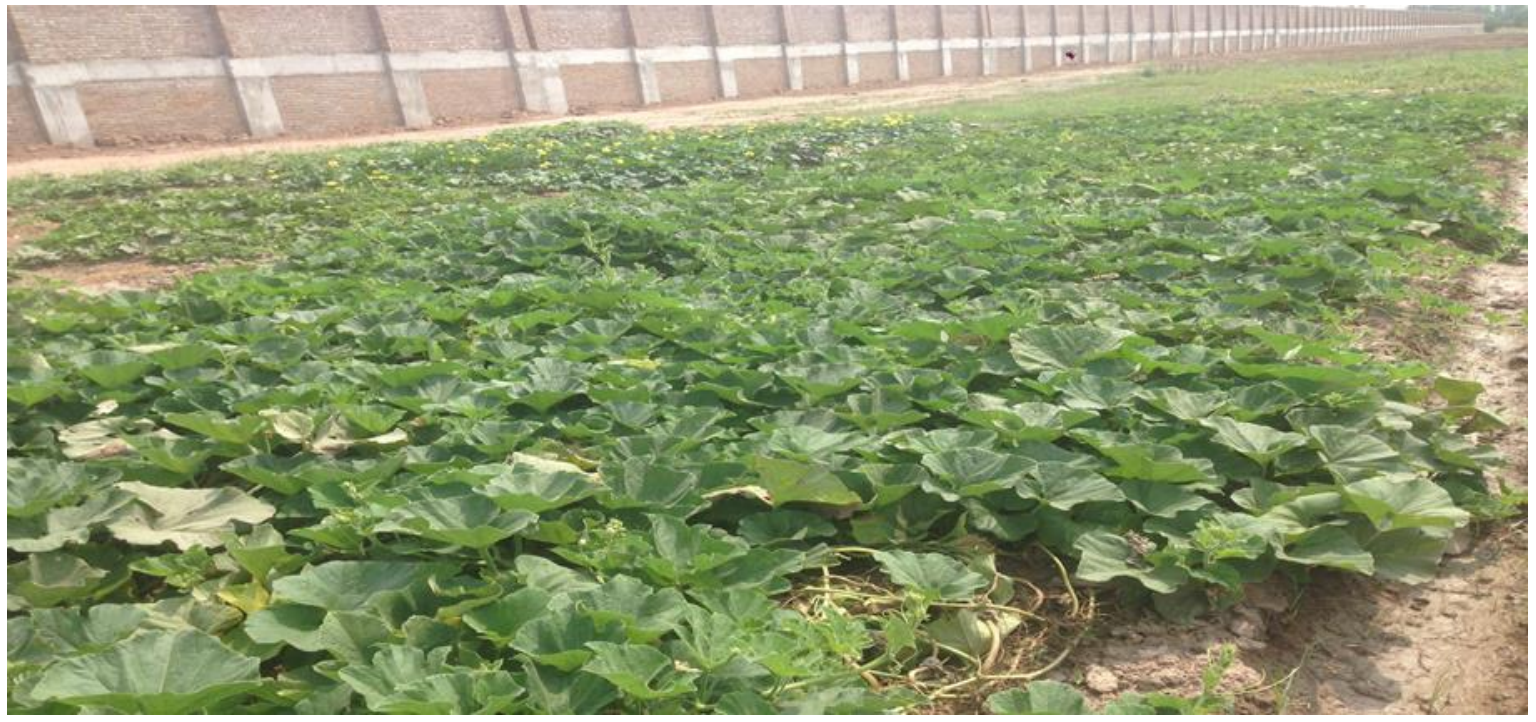

Figure 2. Field of Bottle gourd in (ARI)

Table 1. Disease Severity key for Alternaria leaf spot of Bottle gourd

\begin{tabular}{|c|c|}
\hline Disease Severity Rating & Disease Severity Description \\
\hline 0 & No symptoms \\
\hline 1 & $0.1-0.9 \%$ leaf area affected \\
\hline 2 & $1-10 \%$ leaf area affected \\
\hline 3 & $10.1-25 \%$ leaf area affected \\
\hline 4 & $25.1-50 \%$ leaf area affected \\
\hline 5 & $50.1-100 \%$ leaf area affected \\
\hline
\end{tabular}

\section{Results and Discussion}

After the observation and recording data of bottle gourd from the field of regional research institute (Agricultural Research institute) Tarnab, Peshawar. We record the data from four different cultivars in three repetitions. In mean (Table 2) shows that Alternaria alternata attack had significant 
effect on different long gourd varieties. The maximum disease severity of 45 percent was observed in variety ISC 441 and was categorized as susceptible. In the line C-01 the minimum disease of 11.667 percent was recorded and was categorized as resistant. The damage is up to $80-88 \%$ due to Alternaria alternata [11].

Alternaria leaf spot the disease affects foliage as well fruit [12] Alternaria leaf spot disease is among the most important diseases of bottle gourd [13]. Similar result was obtained by [14] who screened out twenty cultivars of cucumber for resistance to Alternaria leaf spot. 'Pusa Sanyug', Hybrid-5 and Priya were found resistant to most of these diseases. 'Hybrid-5' and 'Priya' were tolerant to downy mildew and anthracnose, while 'Green Express' and 'Marketer 76' were resistant to Alternaria leaf spot, and the genotype of Marketer-76 is also resistant to powdery mildew and Alternaria leaf spot.

Table 2. Percent disease severity of Alternaria leaf spot of bottle gourd

\begin{tabular}{|c|c|c|c|}
\hline S. No. & Cultivars & Percent Disease Severity (\%) & Host Reaction \\
\hline 1 & C-01 & $11.667 \mathrm{C}^{*}$ & Resistant \\
\hline 2 & Super B2 & $26.667 \mathrm{~B}$ & Moderately Resistant \\
\hline 3 & Anokhi & $31.667 \mathrm{~B}$ & Moderately Susceptible \\
\hline 4 & ISC 441 & $45.00 \mathrm{~A}$ & Susceptible \\
\hline
\end{tabular}

LSD value at $0.05=10.04 *$ Figures followed by different letters are significantly different from each other according to Fesher's least significant test at $P=0.05$

\section{Conclusion and Recommendations}

Among the four tested bottle gourd cultivars, C-01 was found resistant against Alternaria leaf spot. Anokhi and super B-2 were highly and moderately susceptible to Alternaria alternate respectively. Variety C-01 was found resistant against Alternaria leaf spot and is highly recommended for growing under field conditions. However further research is needed to support the findings of this experiment in other parts of the country.

\section{Authors' contributions}

Conceived and designed the experiments: M Gul \& IA Khan, Performed the experiments: M Gul, Analyzed the data: M Ibrahim, Contributed reagents/ materials/ analysis tools: A Rehman \& IA Khan, Wrote the paper: M Gul \& IA Khan.

\section{Acknowledgements}

Authors would like to thank the Agriculture Research Institute, Tarnab, Peshawar and Department of Agriculture (Plant Pathology), The University of Swabi for their cooperation to provide opportunity and facilities to conduct this mini research project successfully. Authors would also like to thank the major and minor supervisors for their role in the completion of this project.

\section{References}

1. MNFSR (2015). Ministry of national food security and research economic wing, Govt. of Oils and nutritional composition of seeds from different varieties of Momordica Charantia Linn. Cultivated in Bangladesh. J of Food Sci 26: 275-283.

2. FAO (2011). World Livestock 2011 Livestock in food security. Rome, FAO.

3. Nazimuddin S \& Naqvi SS (1984). Flora of Pakistan. No. 154, Cucurbitaceae. Deptt Bot Univ Karachi, pp. 56.

4. Aykroyd, WR (1963). ICMR Special Rept, Series No. 42.

5. Robinson, DS (1990). Food Biochemistry and Nutritional Value. Longman Scientific and Technical Publisher, New York. USA, pp. 554.

6. Maheshwari, SK, Choudhary, BR \& Singh, D (2013). Occurrence of fungal diseases of bottle gourd in Rajasthan. Progres Hortic 45: 206-208. 
7. Pleysier CE, Bayliss KL \& Dell B et al. (2006). Austr Plant Pathol 35: 329.

8. Alexopoulos CJ \& Mims CW (1979). Introductory Mycology, 3rd Edition John Wiley and Sons, New York, pp. 177-179.

9. Streets RB (1984). The Diagnosis of Plant Diseases. A filed and Laboratory Manual Emphasizing the Most Practical Methods for Rapid Identification. University of Arizona Press, Arizona USA, pp. 8-7.

10. Maheshwari SK \& Choudhary BR (2015). ield Evaluation of Bottle Gourd Genotypes for Resistance against Alternaria Blight in Western Rajasthan. Inter J of Plant Res 28(3): 103-105.

11. Seedbold, K (2010). Foliar Disease of Cucurbits. Plant Pathology Fact Sheet-
Cooperative Extention Service. University of Kentucky. pp. 1-4

12. Bhargava AK \& Singh RD (1985). Comparative study of Alternaria blight losses and causal organisms of cucurbits in Rajasthan. Indian $J$ of Mycol and Plant Pathol 15: 150-154.

13. Maheshwari SK, Choudhary BR, Sharma BD \& Saroj PL (2017). Management of Alternaria leaf blight of Bottle gourd in Western Rajasthan, India. Inter J of Curr Microbiol and Appl Sci 6: 1272-1277.

14. Yousuf S \& et al. (2009). The Studies on fungal foliar Diseases of Cucumber (Cucumis sativus L.) Sher-e-Kashmir University of Agriculture Sciences and Technology of Kashmir, pp. 268. 